\title{
FRUIT PICKING TOOL BASED ON LINEAR MOTOR
}

\author{
Sergey Antonov, Gennady Nikitenko \\ Stavropol State Agrarian University, Russia \\ antonov_serg@mail.ru, nikitenko_gv@mail.ru
}

\begin{abstract}
For the rapid development of gardening, it is necessary to create a set of devices for gardening and harvesting. Harvesting accounts for 15 to $40 \%$ of all garden maintenance work. The use of fruit harvesting machines allows to increase labor productivity during harvesting from 3 to 10 times. Today, there are many designs for harvesting machines in gardens. The industry produces such machines as: MAJA, SP-5, Lisicki, Victor, and many others. All these fruit harvesting machines use vibratory mechanisms. Their disadvantage is: damage to the bark and violation of the root system of the tree. In this regard, there is a problem associated with improvement of the tools for collecting fruits. The intensification of gardening is not possible without increasing the density of planting trees. The distances between the rows of trees are reduced, the existing fruit harvesting machines cannot work effectively under the prevailing conditions. Access to different areas of fruiting is difficult. Using a hand-held electrified fruit picker will be most effective in this case. In addition, a manual device for collecting fruits allows you to eat fruits with minimal damage to the bark and root system of the tree. The main element of the fruit picking device is a linear electric motor. This linear electric motor creates the vibration motion necessary to pick up the fruit. Compared to other types of drive, a linear electric motor has several advantages. The main advantages are low overall dimensions and adjustment of operating parameters.
\end{abstract}

Keywords: gardening, harvesting, fruits, linear electric motor, fruit picker, vibration.

\section{Introduction}

To increase the production efficiency of fruits and berries, it is necessary to develop modern electrified and mechanized hand tools. The value of the harvesting cost reaches $40 \%$ of all costs of caring for the garden. Manual harvesting leads to a decrease in labor productivity and an increase in the cost of production.

For large agricultural enterprises, semi-mechanized and mechanized devices for harvesting fruits and berries are produced [1-3]. Small and farm agricultural enterprises are not able to buy and operate fruit harvesting machines and combines (Fig. 1).
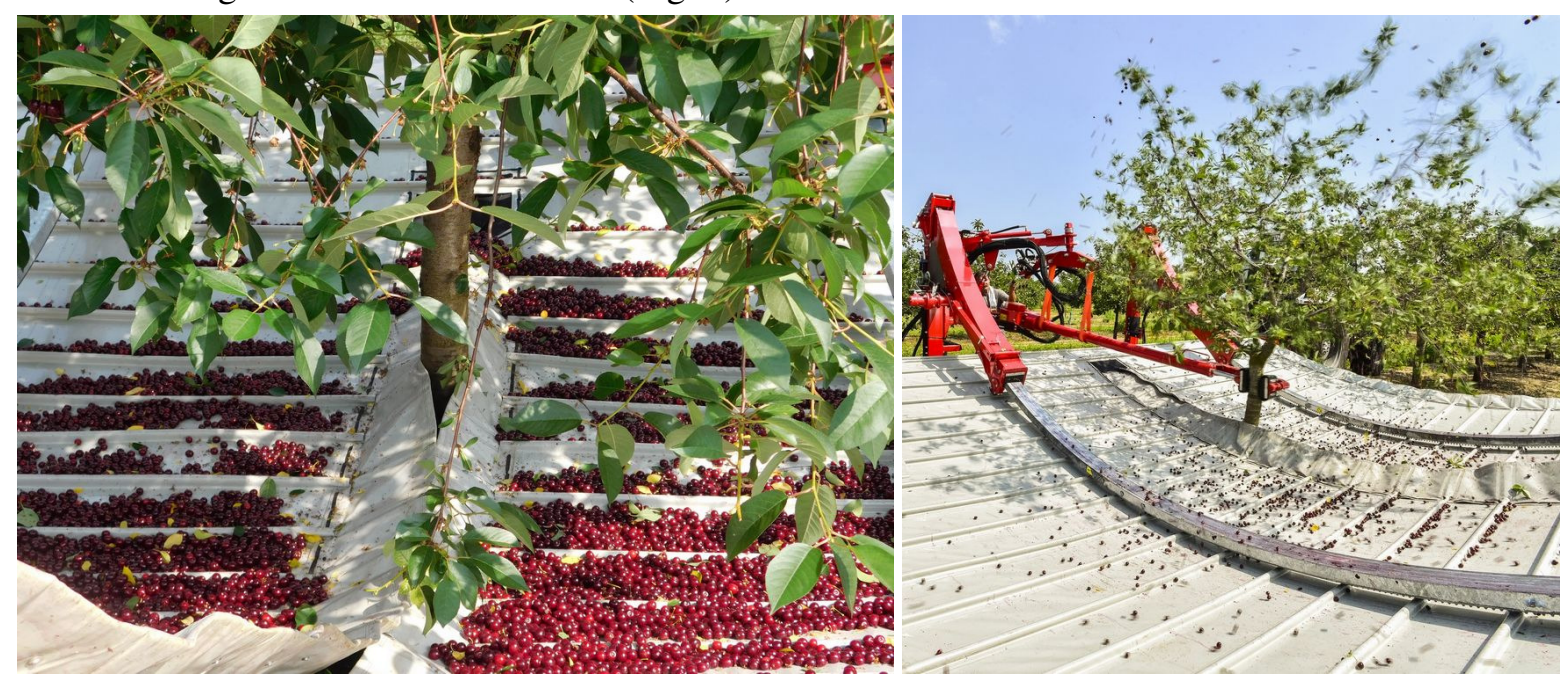

Fig. 1. Shaking and cleaning machine "MAJA AUTOMATIC LK"

In order to increase the efficiency of harvesting in such farms, development and creation of fundamentally new devices is necessary [4-7]. These devices must have high energy efficiency, low weight and a high degree of mobile use. All these properties are possessed by a hand-held electrified tool (Fig. 2).

All existing commercially available machines for picking fruits and berries are based on the principle of vibration of the fruit tree trunks. The shaker is the main element of the device. According to the principle of action, the shakers can be classified into: pneumatic, hydraulic, mechanical and electrical. The most common are hydraulic shakers. 


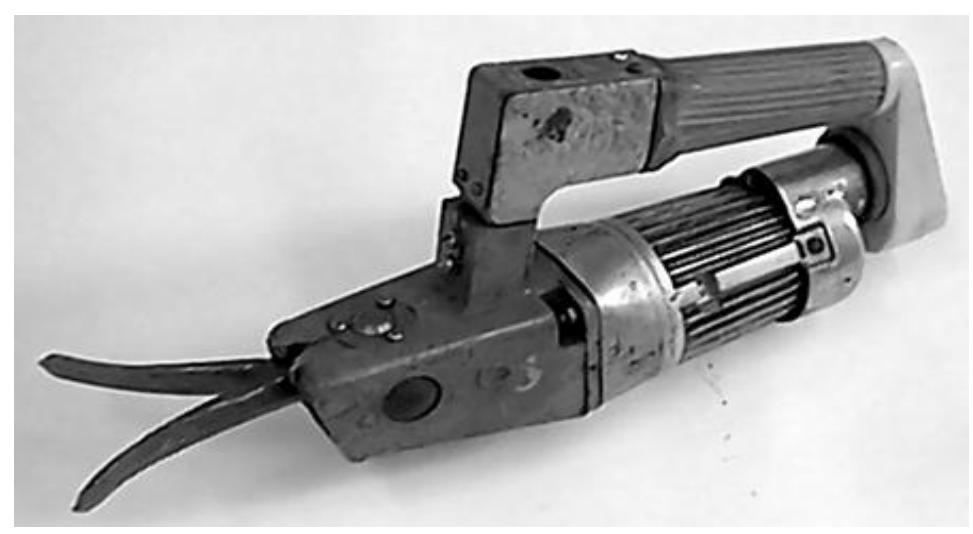

Fig. 2. Vibrator of electric fruit picker ЭЯМ-200-8

The main disadvantages of hydraulic and pneumatic shakers are the low service reliability and the impossibility of operational adjustment of the applied force and vibration amplitude. An incorrect impact force on the trunk leads either to damage to the tree bark or to ineffective shaking of the fruit. Therefore, when developing a modern tool for harvesting fruits and berries, it is necessary to use electric hand tools. In the process of their use, operational adjustment of the applied force to the tree trunk is possible. The most promising is the use of linear electric motors for vibration [8;9].

\section{Materials and methods}

The proposed shaker consists of a gripper (1), which is connected with a screw (2) to the armature (3). The armature (3) is installed using the lower plain bearing (4) in the linear electric motor (5) and the upper plain bearing (6) in the housing (7). The shutdown button (8), a breaker (9) and a battery (10) are also installed in the housing (7). To return to the initial position of the armature (3), a return spring (11) is used, which is located in the protective cup $(12)$, fixed with screws $(13,14)$ on the housing (7) (Fig. 3).

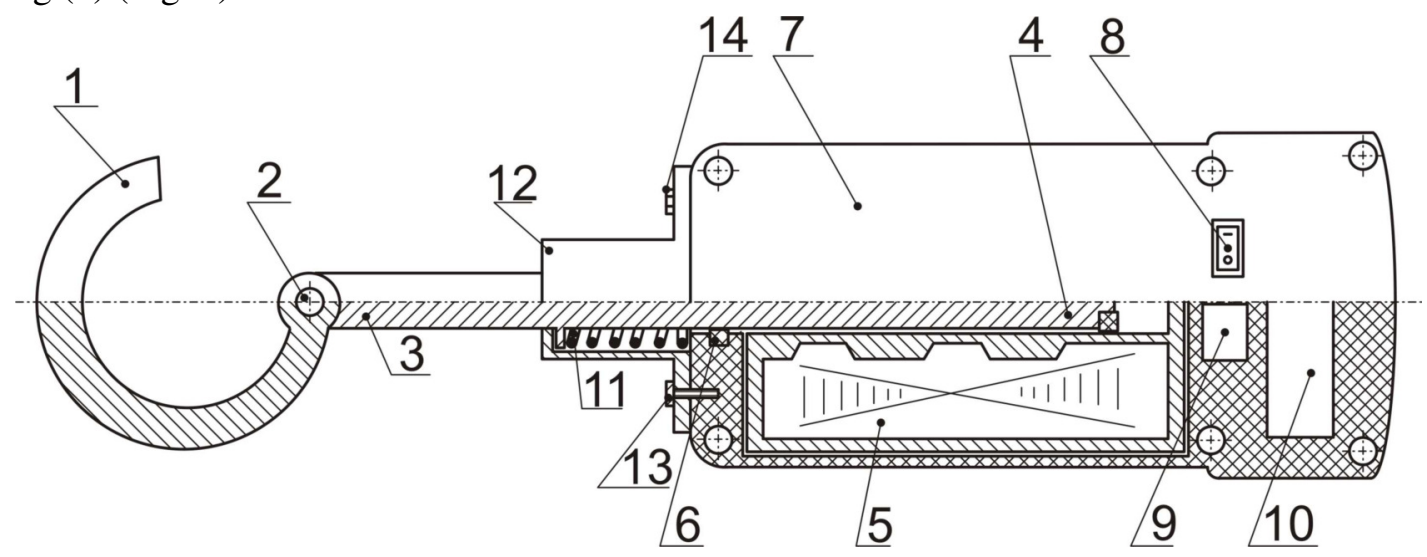

Fig. 3. Linear electric motor shaker

The proposed shaker works as follows: when the power button (8) is pressed, $24 \mathrm{~V}$ voltage is supplied to the linear electric motor (5) through the breaker (9) from the battery (10). The armature (3) connected by a screw (2) with a gripper (1), under the action of electromagnetic forces arising in the linear electric motor (5) comes into motion and moves to the lower position, using the lower plain bearing (4) and the upper plain bearing (6). When the armature (3) reaches its lower position, the breaker (9) disconnects the power of the linear electric motor (5) from the battery (10), while the electromagnetic force acting on the armature (3) disappears under the action of the return spring (11) secured with screws $(13,14)$ in the protective cup $(12)$ and returns to the upper position. Next, the operation of the shaker is repeated with the breaker frequency (9) equal to $4 \mathrm{~Hz}$, until the power button (8) is turned off. When the power button (8) is returned to its initial position, the breaker (9) and the linear electric motor (5) are disconnected from the battery (10) and the armature (3) under the action of the return spring $(11)$ secured with screws $(13,14)$ in the protective cup (12) returns to the upper position. The operating principle of the linear electric motor is considered in detail in the article [8]. 
After analyzing scientific research on the subject of "Fruit harvesting", we can determine the parameters of the shakers for effective work. One of the parameters is the vibration frequency of the branches. For effective shaking it should be in the range from 2.66 to $5.01 \mathrm{~Hz}$. The next parameter is the tension force of the fruit stem. This is the force at which the fruit separates from the branch. For apple trees, this force is in the range from 11.27 to $57.13 \mathrm{~N}$, and the plum is separated in the range from 31.62 to $75.39 \mathrm{~N}[1 ; 2]$.

\section{Results and discussion}

Energy efficiency is one of the important indicators characterizing a hand-held electrified tool. When designing a linear electric motor, it is necessary to obtain maximum force with minimum consumption of electrical energy. Power is the main parameter of the electric motor. Different working conditions of the mechanisms form different operating modes of the electric drive. The main modes of operation are considered - long-term, short-term and repeated-short-term. According to the recommendations when designing electric machines, for a long-term mode (S1) a current density of 3$4 \mathrm{~A} \cdot \mathrm{mm}^{-2}$ is recommended, short-term mode (S2) a current density of $10-12 \mathrm{~A} \cdot \mathrm{mm}^{-2}$, and repeatedshort-term mode $(\mathrm{S} 3)$ a current density 6-8 $\mathrm{A} \cdot \mathrm{mm}^{-2}$. The current passing through the winding of the electric motor causes heating of its parts. Permissible heating of the electric motor is determined by the heat resistance of insulating materials. The greater heat resistance of the insulation makes it possible to reduce the size of the electric motor, or to increase its power while maintaining the dimensions.

Given the design parameters of a linear electric motor, considered in article [8], we will calculate the magnetic motor system in the ElCut program for three operating modes. As a result, we obtain the distribution pattern of the magnetic induction (Fig. 4).

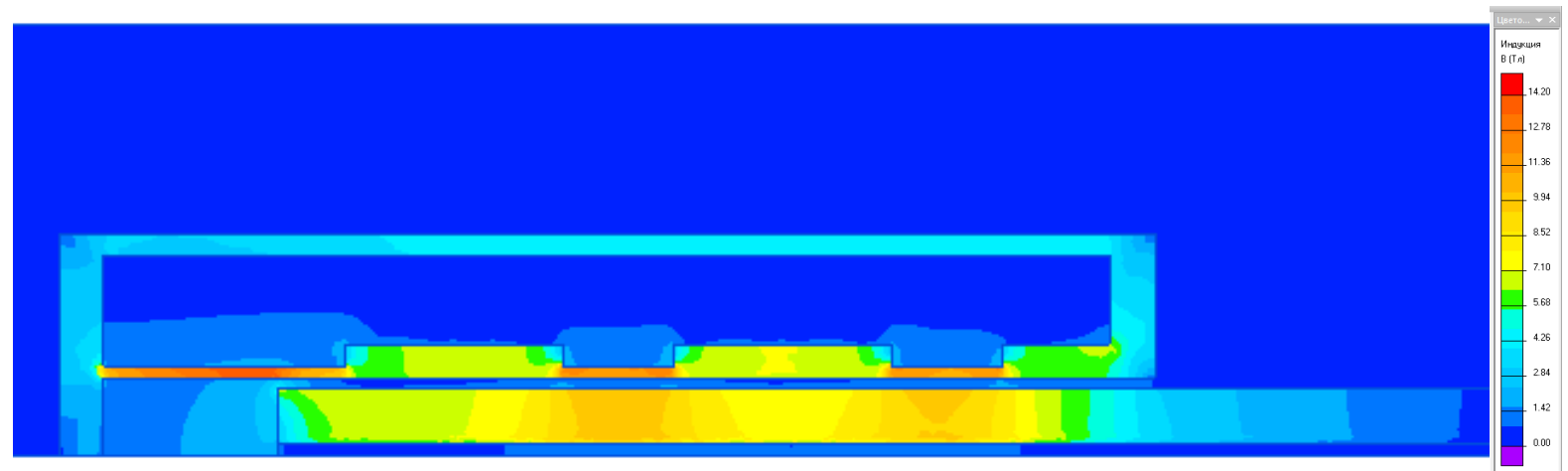

Fig. 4. Distribution pattern of magnetic induction of a linear electric motor

A characteristic reflecting the strength of a magnetic field at any point in space is magnetic induction. The change in magnetic induction in the air gap between the armature and the magnetic system of the coil characterizes the effect measure of the created magnetic field on the armature. Table 1 presents the results of calculating the magnetic induction along the armature of a linear electric motor for three modes (S1, S2, S3).

Results of calculating magnetic induction of a linear electric motor, $T$

Table 1

\begin{tabular}{|c|c|c|c|c|c|c|c|c|c|c|c|c|}
\hline \multirow{2}{*}{$\begin{array}{c}\text { Operating mode } \\
\text { of a linear } \\
\text { electric motor }\end{array}$} & \multicolumn{12}{|c|}{ Armature length, mm } \\
\hline & $\mathbf{0}$ & 10 & 20 & 30 & 40 & $\mathbf{5 0}$ & 60 & 70 & 80 & 90 & 100 & 110 \\
\hline S1 (long-term) & 1. & & & & & & & & 0.42 & & & \\
\hline $\mathbf{S 2}$ & 3 & 0 & 0.77 & 1.18 & 08 & 0.7 & 2 & 1.1 & 0 & 0. & 0.2 & 0.2 \\
\hline $\begin{array}{l}\text { S3 (repeated- } \\
\text { short-term) }\end{array}$ & 2.64 & 0 . & 0.51 & 0. & & 0 . & 0.81 & 0.15 & 0. & 0 & 0.16 & 0.16 \\
\hline
\end{tabular}

To create the force required to separate the fruit from the branch, a traction force acting on the armature of at least $75.39 \mathrm{~N}$ is required. Performing the calculation of the magnetic system with ElCut program, we obtain the traction force acting on the armature (Fig. 5). 

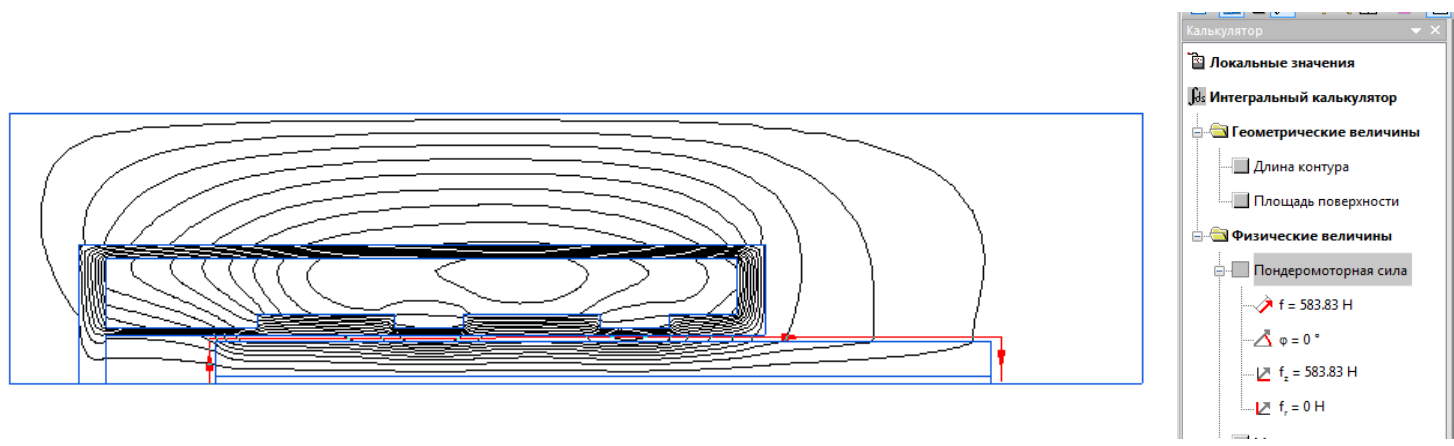

Fig. 5. Determination of the force acting on the armature of a linear electric motor

The characteristics of the linear electric motor in various operating modes (S1, S2, S3) are shown in Fig. 6.

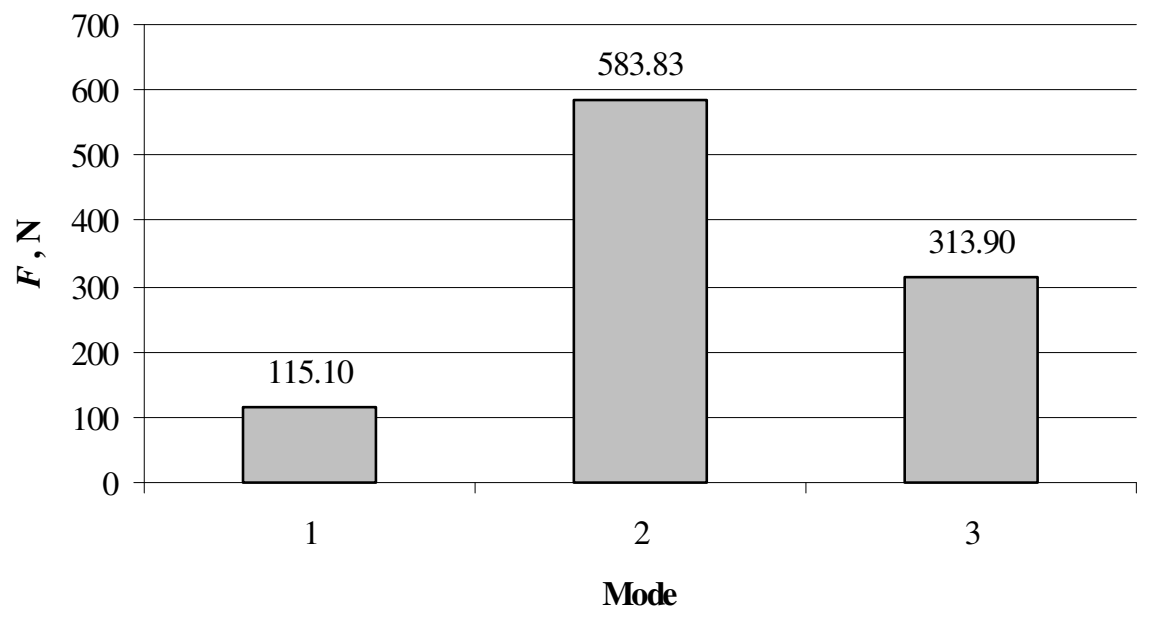

Fig. 6. Strength of magnetic field acting on the armature of a linear electric motor:

1 - long-term mode (S1); 2 - short-term mode (S2); 3 - repeated-short-term mode (S3)

Considering the obtained data, we can say that the greatest value of the armature traction force of a linear electric motor is obtained for a short-term operating mode.

\section{Conclusions}

The presented design of the tool for harvesting fruits can be used by small and medium-sized agricultural enterprises. Modeling the magnetic system of a linear electric motor showed that the force acting on the armature is sufficient to separate the fruit from the branch. The force required to separate the fruit is in the range from 11.25 to $75.39 \mathrm{~N}$, which is less than the force developed by the armature in the modes: S1 $-115.1 \mathrm{~N}, \mathrm{~S} 2-583.83 \mathrm{~N}, \mathrm{~S} 3-313.9 \mathrm{~N}$. Armature vibration frequency of the linear electric motor is $4 \mathrm{~Hz}$.

\section{References}

[1] Котысько В.И. Виброударный штамбовый стряхиватель плодов (Vibrating hammer fruit shaker): diss. cand. agric. sciences. Moscow, 1998. 142 p. (In Russian).

[2] Шевчук Р.С. Процессы и средства механизации съема плодов (Processes and means for mechanizing the removal of fruits): diss. doct. agric. sciences. Moscow, 2000. 404 p. (In Russian).

[3] Hedrick U.P. Cyclopedia of Hardy Fruits. New York: The MacMillan Company, 1922. 370 pp.

[4] Csanády E., Magoss E. Mechanics of Wood Machining. 2-nd ed. Springer-Verlag Berlin Heidelberg, 2013. 199 p.

[5] Antonov S., Nikitenko G., Simulation of linear electric motor for electromechanical pruner. Proceeding of 7th International Conference on «Trends in Agricultural Engineering 2019», 2019. Prague, Czech Republic, 2019, pp. 40-44. 
[6] S. Antonov, G. Nikitenko, V. Grinchenko, A. Molchanov, V. Avdeeva,. Electromechanical secateurs based on a linear electric motor and determination of the cutting force of branches of fruit trees. Engineering for rural development, Jelgava Latvia, 2018, pp. 514-518.

[7] Антонов С.Н., Никитенко Г.В., Авдеева В.Н., Каланчук И.В., Атанов Г.В. Секатор с линейным электродвигателем (Linear motor pruner). Rural mechanic - 2018. - №4. - 89 p. (In Russian).

[8] Antonov S., Nikitenko G., Linear electric motor for handheld electrified tools used in gardening. Engineering for rural development, Jelgava Latvia, 2019, pp. 804-807.

[9] Ряшенцев Н.П., Ковалев Ю.З. Динамика электромагнитных импульсных систем (Dynamics of electromagnetic pulse systems) - Novosibirsk: Science, 1974. - 188 p. (In Russian). 